\title{
Student Perspectives of an Interprofessional Education Experience for Nurse Anesthetist Students and Physical Therapy Students in a Cadaver-Based Anatomy Review Course
}

\author{
Christi Williams ${ }^{1}$, Colleen Gensheimer ${ }^{1}$, John Halle ${ }^{1}$, Patrick Moss ${ }^{2}$ \\ ${ }^{1}$ School of Physical Therapy, College of Health Sciences \& Nursing at Belmont University, Nashville, TN, USA \\ ${ }^{2}$ LifeLinc Academy, Memphis, TN, USA \\ Email: christi.williams@belmont.edu,john.halle@belmont.edu,pmoss@lifelinc.com
}

How to cite this paper: Williams, C., Gensheimer, C., Halle, J. and Moss, P. (2018) Student Perspectives of an Interprofessional Education Experience for Nurse Anesthetist Students and Physical Therapy Students in a Cadaver-Based Anatomy Review Course. Open Access Library Journal, 5: e4782. https://doi.org/10.4236/oalib.1104782

Received: July 16, 2018

Accepted: August 5, 2018

Published: August 8, 2018

Copyright $\odot 2018$ by authors and Open Access Library Inc.

This work is licensed under the Creative Commons Attribution International License (CC BY 4.0).

http://creativecommons.org/licenses/by/4.0/

\begin{abstract}
Background: There is growing evidence supporting the many benefits of interprofessional education (IPE) amongst students of varying medical professions. Since anatomy education is necessary for all healthcare providers, an anatomy laboratory can provide an excellent environment for IPE activities. Unfortunately, due to the high cost of maintaining an anatomy laboratory, many programs do not have access to learn in a cadaver-based environment. The purpose of this study was to examine the outcomes of an interprofessional teaching and learning opportunity between doctorate of physical therapy (DPT) students and certified registered nurse anesthetist (CRNA) students during a cadaver-based anatomy review course. Methods: A group of DPT students taught different sections of clinically relevant anatomy to the CRNA students under the direction and provision of faculty from both programs. At the completion of the course, students from both disciplines were given an anonymous survey to complete regarding their overall experience in a cadaver-based setting as well as their thoughts regarding the interprofessional teaching/learning opportunity with students in another healthcare discipline. Results: Of the 11 DPT students and 60 CRNA students who completed a survey, $82.0 \%$ of the DPT students and $86.0 \%$ of the CRNA students felt they better understood another healthcare profession after the experience and that IPE is beneficial for other healthcare professions. One hundred percent of the CRNA students found it beneficial to have a cadaver-based anatomy course and felt the course enhanced their three-dimensional understanding of human anatomy, which they believed would be beneficial in fu-
\end{abstract}


ture anesthesia procedures. In addition, 100\% of the DPT students agreed that teaching the cadaver-based anatomy course helped with their own retention of human anatomy, and $82.0 \%$ felt that by teaching the course, it helped improve their communication skills with other healthcare providers. Conclusions: The results suggest that exposure to anatomy through cadaver-based learning for CRNA students may be valuable to their clinical understanding of anatomy. Additionally, the results support the benefits of IPE to include: learned respect of fellow colleagues, exposure to another profession's expertise, decreased barriers to communication and a new understanding of how two varying professions can work together clinically.

\section{Subject Areas}

Education, Nursing

\section{Keywords}

Interprofessional Education, Cadaver, Anatomy, Physical Therapy, Certified Registered Nurse Anesthetist

\section{Background}

Interprofessional collaboration is necessary in the healthcare setting to provide optimal patient care given that the complex needs of many patients often require the skills and expertise of multiple medical professionals [1]. Healthcare workers must have ample opportunity to learn about, from and with one another for effective collaboration to occur in which the sharing of expertise and perspectives can improve health outcomes [2]. Given that the overall goal of interprofessional collaboration is to improve patient care, this model should optimally be introduced at the student level so that future healthcare providers learn the many benefits that interprofessional collaboration can have on patient outcomes [1].

The World Health Organization (WHO) defines interprofessional education, also known as IPE, as an educational collaboration that "occurs when students from two or more professions learn about, from and with each other to enable effective collaboration and improve health outcomes" [2] [3]. Various IPE teaching and learning opportunities have led to an understanding of the expertise of other professionals serving on the healthcare team, and increased clarity on how the roles of the individuals' own profession contribute to the ultimate goal of the team [4]. Some of the benefits of IPE include improved communication, cooperation, role-clarification, team functioning, conflict resolution and mutual trust and respect [4] [5], all of which help to remove the compartmentalization or silos that often exist between healthcare professionals in various areas of specialty.

Despite the fact that IPE is well supported in the literature, there are still several barriers that exist that limit the overall implementation of IPE experiences 
in healthcare education. For instance, creating IPE experiences requires a significant amount of time, planning, and coordination between various programs and/or institutions to secure a location that is appropriate to allow for classes to exist, in which students of various healthcare professions can be intermingled [6]. In addition to finding an appropriate location, there is the significant challenge of adjusting and coordinating the students' and professors' schedules to accommodate this type of coursework, which often leads to the need for the overall curricula of the different programs themselves to be adjusted [6].

Given the challenges that exist with scheduling and coordinating IPE experiences, an opportunity exists with courses that are common to multiple healthcare educational curriculums and that provide foundational didactic information and experiences. Additionally, looking for opportunities with courses that occur early within a program may prove to be a good option to help minimize the extent in which the curriculum may need to be adjusted to accommodate these experiences. One example of a foundational course that may serve as a good opportunity for IPE experiences between various programs is human anatomy. Human anatomy is a course that is common to the majority of healthcare educational programs, it is foundational knowledge, and it is often scheduled early in a program's curriculum. Given that this is an area of common didactic need, creating IPE experiences in a human anatomy laboratory may create a culture of interprofessional teamwork and collaboration early in the educational program that can later be further built upon in other classes throughout the curriculum. In addition, having early IPE experiences may even help to encourage outside interactions and study sessions between different professional groups, which was found to be the case when first-year medical students and physical therapy students were exposed to IPE in a gross anatomy course at Mayo Clinic [7].

Despite the fact that knowledge of human anatomy is necessary for all healthcare providers, not all healthcare educational programs have equal emphasis on anatomy education and the way in which anatomy is being taught varies considerably between various healthcare educational programs [8] [9]. For instance, teaching anatomy using cadaveric dissections is typical in medical programs as well as many physical therapy and occupational therapy programs, however it is not a typical experience for many nursing students [10]. The anatomy curriculum for many nursing programs has historically been based on the use of text, simulation or infrequently, animal dissection [11]. Consequently, many nursing students are left with a superficial learning of surface anatomy and are less able to visualize the deeper structures that exist and how these deeper structures are spatially-related to other organs in the human body [11]. The benefit of learning anatomy via human dissection or by studying prosected, or previously dissected specimens, is that it allows for kinesthetic learning of the structures of the body, and allows students to better comprehend the size, structure, thickness and layering of various structures, as well as demonstrating the anatomical variation that exists between people [8] [9] [11] [12]. 
Despite the many perceived benefits of learning human anatomy from dissection of cadavers, there is a significant obligation required financially and administratively to maintain the necessary laboratory space requirements, and these obligations can limit the ability for certain programs to have access to cadaver-based anatomy educational experiences [9] [13]. In addition, the number of qualified faculty to teach dissection has been decreasing while at the same time the number of students enrolled in healthcare programs is on the rise [8] [14]. For these reasons, as well as others, human anatomy is frequently taught in cadaver-less environments in which simulation and other computer-based programs are used [8] [9].

While the best method of teaching anatomy remains open for debate, when it comes to clinical application, cadaver-based anatomy instruction allows for the three-dimensional kinesthetic understanding of a patient's structures and tissues [9] [11] and creates an excellent opportunity for small group collaboration and problem solving [15], which may provide an excellent opportunity for IPE experiences. Hamilton et al. provided an interprofessional educational experience in gross anatomy for first-year medical and physical therapy students and found that overall the students rated it as a positive experience with $92 \%$ of the students agreeing that interprofessional learning would help them interact with other professionals in the future [7]. Students in this study noted that they enjoyed "a different perspective on the course material" and the opportunity to develop "mutual understanding and teamwork" with the other health care students [7].

The following describes a unique teaching and learning opportunity that resulted in an IPE experience for doctor of physical therapy (DPT) students at Belmont University in Nashville, TN and certified registered nurse anesthetist (CRNA) students at Middle Tennessee School of Anesthesia (MTSA) in Madison, TN. In this particular case example, the faculty at MTSA were seeking an opportunity for their students to review clinically relevant anatomy on cadavers because many of their students, despite having completed a nursing program prior to admittance to the program, had never had exposure to cadaver-based learning. Understanding human anatomy in three-dimensions and improving spatial awareness related to the depth and thickness of various structures is pertinent for these students to understand in preparation for learning how to perform ultrasound guided anesthesia injections. The CRNA program at MTSA is a stand-alone program and there is not a cadaver laboratory on campus for them to access.

Belmont University houses a cadaver laboratory primarily for use in the DPT program in which full cadaveric dissections are performed by the first-year DPT students. At the end of the fall semester once all dissections were completed, 12 second-year DPT students who had all completed the anatomy course the prior year, volunteered to return to the cadaver lab to provide the relevant anatomy review to small groups of CRNA students. Having second-year DPT students allowed for the additional advantage of them having completed coursework in 
clinical application and clinical experiences, all of which they could share when teaching. This educational exchange provided by DPT students to CRNA students allowed multiple regions to be overviewed and discussed by the two groups. Immediately following the conclusion of the course, a survey was given to each of the CRNA students as well as the DPT students to provide information regarding the course itself as well as the IPE experience. The purpose of this study was to gain insight into the value of a cadaver-based learning experience for CRNA students, and the IPE impact to both CRNA and DPT students.

\section{Methodology}

Sixty CRNA students and 12 DPT students participated in the four-hour clinical anatomy review course hosted at Belmont University's John S. Halle Human Anatomy Laboratory located in Nashville, TN. The course consisted of six stations, each taught by a second-year DPT student, using two prosected cadavers and various visual aids including 3-D models and textbook images projected onto nearby screens. The 60 participants were divided into two groups of 30 to minimize the number of CRNA students in the laboratory at the same time. The four-hour course was provided to 30 participants on one day and was repeated the next day for the remaining 30 student participants. There were six DPT students, one for each of the six stations, present to provide instruction each day, which included an anatomy review with clinical application for the following regions: 1) brain, spinal cord, and muscles of the back, 2) anterior neck and upper extremity, 3) anterior lower extremity, 4) thorax, heart and lungs, 5) abdomen and pelvis, and 6) posterior lower extremity. Once in the laboratory, CRNA students divided themselves across the six stations resulting in a group of five CRNA students at each station. The course consisted of 30 minutes of anatomy review and hands-on time with the cadaver prosections at each station. Students rotated throughout the stations with a short break mid-way through the course. Throughout the course there were two DPT faculty present and one CRNA faculty to assist with questions and further demonstrate clinical applicability for the CRNA students related to the regional anesthesia blocks they would soon be learning. At the end of the course, participants were allowed to return to any of the stations for additional questions or more time reviewing the structures as needed.

Following the course, a survey was provided to each of the CRNA students as well as the DPT students, which included several Likert-based questions as well as several qualitative, open-ended questions about the organization of the course itself and to gather feedback regarding the IPE experience. Examples of qualitative questions include the following: 1) List one thing you learned about the profession of physical therapy/anesthesia that you were not aware of prior to this course; 2) Explain how this course helped your communication skills and comfort level in communicating with other healthcare professionals; 3) Provide an example of how something you learned from the physical therapy/CRNA students will benefit your future patient care. Sixty of the 60 CRNA students com- 
pleted the survey for a response rate of $100 \%$ and 11 of the 12 DPT students completed the survey for a response rate of $91.7 \%$. Surveys were approved by the Belmont Institutional Review Board (protocol \#176). All students had the anonymous option to avoid participation in the surveys and/or to decline answering specific questions within the surveys.

\section{Statistics}

Descriptive data were obtained from either five or ten-point Likert Scales, and were processed using IBM’s SPSS 22.0 Program. For the five-point Likert Scale, 1 and 2 represented "strongly disagree" or "disagree", 3 represented "neutral", and 4 and 5 represented "agree" and "strongly agree" respectively. Operationally, the 4 and 5 values were considered as indication of a positive response and were grouped together for a percentage response for each question posed. A value of 3 was considered neutral, and a 1 or 2 value were considered as a negative response. For the ten-point Likert Scales, a similar operational grouping was done, with the four middle values $(4,5,6$, or 7$)$ all considered as a "neutral response", with values below a 4 representing a "negative response", and values above a 7 representing a "positive response". Should a response be left blank, it was considered to be a "no response" and was not considered as part of the number of responses for the question within the survey. For each question posed in the surveys, the percentage of "positive responses" was obtained and presented. Additionally, qualitative data were provided and reviewed with the surveys, and examples of the qualitative data are included within the Results and Discussion sections.

\section{Results}

For the CRNA Student Surveys, 60 students provided data through answering the survey questions, and specific responses are provided in Table 1 and Table 2. Table 1 was a ten-point Likert Scale that had five questions that dealt with the cadaver experience and the students' response to factors such as retention, improving the understanding of anatomy, and examining the IPE experience. The overall mean "positive response" was $86.3 \%$, with positive response rates ranging from $80.4 \%$ to $93.0 \%$ (Table 1). Table 2 was a five-point Likert Scale that assessed the CRNA's view of factors such as the student faculty that presented the course, potential benefits of being in a lab environment with cadavers, and whether or not this would be an experience that would be recommended. The overall mean "positive response" was $98.0 \%$, with positive response rates ranging from $93.2 \%$ to $100.0 \%$ (Table 2).

Table 3 was a ten-point Likert Scale that examined the 11 DPT student instructor perceptions of the cadaver teaching experience, in terms of how they viewed this experience as enhancing their understanding, teaching skills, and other factors such as understanding another healthcare profession. In this survey, there were eight questions (Table 3), and the overall mean "positive 
Table 1. Results from 10-point Likert scale CRNA student survey $(\mathrm{N}=60)$.

\begin{tabular}{|c|c|c|c|c|c|c|c|c|c|c|c|c|}
\hline & $\begin{array}{c}1 \\
\text { Not } \\
\text { At All }\end{array}$ & 2 & 3 & 4 & $\begin{array}{c}5 \\
\text { Neutral }\end{array}$ & 6 & 7 & 8 & 9 & $\begin{array}{c}10 \\
\text { Significantly }\end{array}$ & $\begin{array}{c}\text { No } \\
\text { Response }\end{array}$ & $\begin{array}{l}\% \text { positive } \\
\text { response }^{\mathrm{a}}\end{array}$ \\
\hline $\begin{array}{l}\text { To what extent did a course in a cadaver lab } \\
\text { help to enhance your retention of anatomy? }\end{array}$ & 0 & 0 & 0 & 0 & 1 & 2 & 8 & 18 & 11 & 16 & 4 & $80.4 \%$ \\
\hline $\begin{array}{l}\text { To what extent did this course help you to } \\
\text { better understand another healthcare profession? }\end{array}$ & 1 & 0 & 0 & 1 & 0 & 0 & 6 & 14 & 20 & 15 & 3 & $86.0 \%$ \\
\hline $\begin{array}{l}\text { To what extent did a cadaver course enhance } \\
\text { your understanding of human anatomy? }\end{array}$ & 0 & 0 & 0 & 0 & 0 & 0 & 5 & 15 & 19 & 18 & 3 & $93.0 \%$ \\
\hline $\begin{array}{l}\text { To what extent did this experience help } \\
\text { integrate anatomy with your current coursework? }\end{array}$ & 0 & 0 & 0 & 0 & 1 & 1 & 6 & 16 & 17 & 16 & 3 & $86.0 \%$ \\
\hline $\begin{array}{l}\text { Do to what extent did you feel that an } \\
\text { inter-professional experience is } \\
\text { beneficial for healthcare professionals? }\end{array}$ & 0 & 0 & 0 & 0 & 4 & 0 & 4 & 11 & 9 & 29 & 3 & $86.0 \%$ \\
\hline
\end{tabular}

${ }^{\mathrm{a}} \mathrm{A}$ score of 8,9 or 10 indicates a positive response.

Table 2. Results from 5-point Likert scale CRNA student survey $(\mathrm{N}=60)$.

\begin{tabular}{|c|c|c|c|c|c|c|c|}
\hline & $\begin{array}{c}1 \\
\text { Strongly Disagree }\end{array}$ & $\begin{array}{c}2 \\
\text { Disagree }\end{array}$ & $\begin{array}{c}3 \\
\text { Neutral }\end{array}$ & $\begin{array}{c}4 \\
\text { Agree }\end{array}$ & $\begin{array}{c}5 \\
\text { Strongly Agree }\end{array}$ & $\begin{array}{c}\text { No } \\
\text { Response }\end{array}$ & $\begin{array}{l}\% \text { positive } \\
\text { response }^{\mathrm{a}}\end{array}$ \\
\hline $\begin{array}{l}\text { The student instructors were well prepared and } \\
\text { able to answer my questions about anatomy }\end{array}$ & 0 & 0 & 0 & 12 & 47 & 1 & $100 \%$ \\
\hline $\begin{array}{l}\text { There was enough support from faculty to integrate } \\
\text { specific relevant information from my coursework }\end{array}$ & 0 & 0 & 4 & 15 & 40 & 1 & $93.2 \%$ \\
\hline $\begin{array}{l}\text { It was beneficial to have an anatomy course } \\
\text { in the cadaver lab. }\end{array}$ & 0 & 0 & 0 & 12 & 46 & 2 & $100 \%$ \\
\hline $\begin{array}{l}\text { This exposure to a cadaver has enhanced my } \\
\text { 3-Dimensional understanding of human } \\
\text { anatomy and will be beneficial in future } \\
\text { anesthesia procedures. }\end{array}$ & 0 & 0 & 0 & 12 & 47 & 1 & $100 \%$ \\
\hline $\begin{array}{l}\text { I would recommend this experience } \\
\text { to others in my field }\end{array}$ & 0 & 0 & 2 & 10 & 47 & 1 & $96.6 \%$ \\
\hline
\end{tabular}

${ }^{\mathrm{a}} \mathrm{A}$ score of 4 or 5 indicates a positive response.

response" was $83.0 \%$, with positive response rates ranging from $64 \%$ to $100 \%$ (Table 3). For Table 3, there were no "negative responses" for any of the questions posed.

\section{CRNA student survey responses:}

The results of the CRNA student survey demonstrate that the cadaver-based anatomy review course was not only beneficial to the students' anatomy knowledge, but also beneficial as an interprofessional experience. Table 1 displays the findings of the 10-point Likert scale results in terms of individual responses and percent positive responses. In regards to anatomy education itself, $93.0 \%$ of the CRNA students felt the cadaver-based course helped with their understanding of human anatomy and $86.0 \%$ felt the cadaver-based anatomy course helped to integrate anatomy with their current coursework, while $80.4 \%$ felt that the course 
Table 3. Results from 10-point Likert scale DPT student survey $(\mathrm{N}=11)$.

\begin{tabular}{|c|c|c|c|c|c|c|c|c|c|c|c|c|}
\hline & $\begin{array}{c}1 \\
\text { Not } \\
\text { At All }\end{array}$ & 2 & 3 & 4 & $\begin{array}{c}5 \\
\text { Neutral }\end{array}$ & 6 & 7 & 8 & 9 & $\begin{array}{c}10 \\
\text { Significantly }\end{array}$ & $\begin{array}{l}\text { No } \\
\text { Response }\end{array}$ & $\begin{array}{l}\% \text { positive } \\
\text { response }^{\mathrm{a}}\end{array}$ \\
\hline $\begin{array}{l}\text { To what extent did you find that teaching } \\
\text { the material at your station helped to } \\
\text { enhance you own understanding of anatomy? }\end{array}$ & 0 & 0 & 0 & 0 & 0 & 0 & 1 & 2 & 4 & 4 & 0 & $90.0 \%$ \\
\hline $\begin{array}{l}\text { To what extent did you find that teaching } \\
\text { the material at your station helped to enhance } \\
\text { your own retention of anatomy? }\end{array}$ & 0 & 0 & 0 & 0 & 0 & 0 & 0 & 1 & 4 & 6 & 0 & $100 \%$ \\
\hline $\begin{array}{l}\text { To what extent did you find that teaching } \\
\text { this course improved your teaching skills? }\end{array}$ & 0 & 0 & 0 & 0 & 0 & 0 & 0 & 1 & 5 & 5 & 0 & $100 \%$ \\
\hline $\begin{array}{l}\text { To what extent did you find that teaching } \\
\text { this course improved your communication } \\
\text { skills with other healthcare providers? }\end{array}$ & 0 & 0 & 0 & 0 & 0 & 0 & 2 & 3 & 4 & 2 & 0 & $82.0 \%$ \\
\hline $\begin{array}{l}\text { To what extent did this experience change your } \\
\text { comfort level/confidence in communicating } \\
\text { with other healthcare professionals? }\end{array}$ & 0 & 0 & 0 & 0 & 1 & 0 & 3 & 2 & 3 & 2 & 0 & $73.0 \%$ \\
\hline $\begin{array}{l}\text { To what extent did this course help you to better } \\
\text { understand another healthcare profession? }\end{array}$ & 0 & 0 & 0 & 0 & 0 & 1 & 1 & 3 & 3 & 3 & 0 & $82.0 \%$ \\
\hline $\begin{array}{l}\text { To what extent did this experience help you to } \\
\text { integrate anatomy with your current coursework } \\
\text { in orthopedics, neuroscience and pathology? }\end{array}$ & 0 & 0 & 0 & 0 & 2 & 2 & 0 & 1 & 5 & 1 & 0 & $64.0 \%$ \\
\hline $\begin{array}{l}\text { To what extent did you feel that an } \\
\text { inter-professional teaching/learning experience } \\
\text { was beneficial for healthcare professionals? }\end{array}$ & 0 & 0 & 0 & 0 & 1 & 0 & 1 & 1 & 3 & 5 & 0 & $82.0 \%$ \\
\hline
\end{tabular}

${ }^{\mathrm{a}} \mathrm{A}$ score of 8,9 or 10 indicates a positive response.

helped with their overall retention of anatomy. In regards to the IPE experience, Table 1 demonstrates that $86.0 \%$ of the nurse anesthetist students felt that the course helped them to not only better understand another healthcare profession but also $86.0 \%$ reported that they felt that interprofessional educational experiences are beneficial for healthcare professionals.

Table 2 displays the findings of the 5-point Likert scale questions given to the CRNA students. One hundred percent of the CRNA student participants felt that the DPT student instructors were well prepared and able to answer questions and $93.2 \%$ felt that there was sufficient support from faculty to further integrate specific relevant information from their coursework. Overall responses indicated that $100 \%$ of the CRNA students felt that it was a beneficial experience to have an opportunity to learn anatomy on human cadavers and the course enhanced their three-dimensional understanding of human anatomy which would be beneficial to the future anesthesia procedures that they will be learning. When asked to indicate if they would recommend this course to others in their field of study, 96.6\% indicated that they would recommend the course to others.

In regards to qualitative responses from the CRNA students, when asked to list something that they learned about the profession of physical therapy they 
were not aware of prior to this course, 49 of the 60 participants $(81.7 \%)$ included a comment pertaining to the fact that they were not aware of how extensive a physical therapist's education level was in anatomy and physiology and/or how in-depth a physical therapist's knowledge was of the entire body. One student commented, "I was not aware PT students' education required such a detailed knowledge of anatomy. I was very impressed by the knowledge of the students. I developed a whole new respect for the profession of Physical Therapy." Another student noted, "I understand [now] that it [physical therapy] is a broad field. It is more than just sports medicine."

When asked to further provide an example of how something they learned from the physical therapy students will benefit their future patient care as a CRNA, several students commented that by understanding how physical therapists provide care post-operatively, it will influence their decisions regarding the type of regional anesthesia block to provide for a particular patient during surgery. Some comments included, "They were teaching us about some blocks that may be done for lower extremities and then how it would change the care they provided post-op (especially in regards to being able to ambulate)", while another student noted, "That what I do in the operating room has a direct effect on the return to best function of my patients and that knowing what a PT needs post-op should guide what I do intra-op." Another common theme to this question was that by working with the DPT students, they were more aware of the patient's recovery long-term such as when rehabilitating post-operatively with a physical therapist. One student commented that by working with the DPT students it allowed for, "Thinking of the rehabilitation aspects of my patient's operative course and seeing a larger view focused on recovery, not just the Post Anesthesia Care Unit'.

\section{DPT student survey responses:}

Table 3 displays the results of the 10-point Likert scale questions from the DPT students. In regards to the teaching experience of the DPT students in the cadaver-based anatomy course, $90.0 \%$ of the DPT students felt teaching anatomy to the CRNA students actually helped with their own understanding of anatomy while $100 \%$ felt teaching helped with further retention of their anatomy knowledge. Pertaining to IPE, $82.0 \%$ of the DPT students felt that the teaching experience allowed them to better understand another healthcare profession and 73.0\% of the DPT students felt more comfortable and/or confident in communicating with other healthcare professionals after the course. Similar to Table 1, $82.0 \%$ of the physical therapy students felt IPE experiences would be beneficial for healthcare professionals.

In regards to qualitative comments from the DPT students regarding what they learned by teaching the anatomy review course to the CRNA students, several comments related to the various anesthesia procedures that are performed for patients that the physical therapists will see post-operatively and how these different procedures will impact their physical therapy interventions. Students noted that they learned where nerve blocks are injected around the brachial 
plexus, how to intubate a patient and how spinal taps are performed. One student commented that they learned, "a nerve block at a certain place will affect the mobility of my patient post-surgery. Now I am aware of that and I understand what effects it will have on my patient." DPT students also commented that they did not know how much education was required for CRNA's or that they were required to have prior work experience as a nurse before being eligible to enroll in a CRNA program.

\section{Discussion}

The purpose of this study was to gain insight into the value of providing a cadaver-based anatomy review course for CRNA students who did not have access to a cadaver laboratory on campus, by creating an interprofessional teaching and learning opportunity with DPT students at another institution. As the results of this study demonstrate, the responses from both the CRNA students and the DPT students were overwhelmingly positive and demonstrate some of the many benefits of integrating cadaver-based learning into a program for nursing students for improved three-dimensional understanding and visualization of various anatomical structures, as well as the benefits of incorporating interprofessional teaching and learning experiences into the curriculum of various healthcare professions to improve communication, teamwork and mutual respect and understanding.

\section{Benefits of cadaver-based anatomy education:}

Despite the need for more research comparing the clinical retention of cadaver-based anatomy versus cadaver-less anatomy, the IPE collaboration of the DPT students and the CRNA students provided a cost-effective opportunity for students enrolled in a CRNA program who would not normally have access to a cadaver-based anatomy lab to review their core anatomy curriculum through a combination of hands-on kinesthetic learning with cadavers as well as simulation of some of the procedures they were currently learning. For the CRNA students, both the quantitative and qualitative surveys demonstrated that cadaver exposure within their curriculum was beneficial to their learning and three-dimensional understanding of human anatomy, which they felt would be beneficial in the future when exposed to additional anesthesia procedures. Several of the CRNA students commented that they appreciated having the opportunity to have a hands-on experience with cadavers given that many of them had not had this experience prior to the review course. Students commented that they thought it was helpful to be able to visualize the anatomy and what the body actually looks like with one student describing this as, "Seeing the impossible complexity and beauty of human anatomy in person rather than via the artistic rendering in textbooks." Overall outcomes were very similar to those found in a study by Johnston in which nursing students also had very positive responses in regards to a single exposure to cadaveric dissections as a voluntary laboratory experience [11]. 
The CRNA students also noted that they were better able to understand the actual size of the anatomical structures and gain a better understanding of the spatial relations and regional interactions of the anatomical features, which is similar to what is reported in the literature in regards to the benefits of learning in a cadaver-based course [8] [9] [12]. One student commented that they realized that the nerves were much smaller than they expected yet were very tangible and at times very large, such as is the case with the sciatic nerve. Students noted that it was helpful to their understanding of how to perform a spinal block because they could see the spinal anatomy and the caudaequina itself and were even provided with an opportunity to insert a needle to practice a spinal tap on one of the cadavers. In response to being asked what the best part of the course was, one student commented, "The ability for hands-on experience, seeing the body and manipulating the muscles, etc., which was an opportunity I would have never otherwise had".

\section{Benefits of the IPE Experience:}

One of the goals of interprofessional educational experiences is to develop a healthcare professional who has learned how to work in an interprofessional team and is competent in their skill set to provide the best patient care possible [2]. In regards to the benefits of the IPE experience in the anatomy laboratory, a few key themes from the student survey responses included the benefits of improved communication, teamwork and mutual respect for other healthcare providers. These themes are just a few examples of the benefits of IPE found in the literature [4] [5].

Communication is key when it comes to any group collaboration or teamwork initiative and in healthcare, the lack of communication between medical professionals can be very costly [16]. Similar to other student perspectives following an IPE experience, the CRNA students and DPT students in this example commented that the IPE experience in the cadaver laboratory had an impact on their communication skills with other healthcare professionals [1]. When asked about how the course helped with communication skills or even just their comfort level in communicating with other healthcare professionals, several students commented that the experience did indeed help them to feel more comfortable talking to other healthcare professionals. One CRNA student commented, "It [IPE] allows the two professions to communicate and work together to provide the best care for a patient. They [DPT students] helped us understand anatomy from a PT standpoint and we discussed its importance from an anesthesia standpoint." Another CRNA student mentioned, "I wasn't aware physical therapists were capable of discussing medical care to such depth. I will be able to use medical language with more branches of the healthcare team than I realized".

The DPT students were also asked to explain how the course helped with their communication skills. Several students noted that by repeating the same 30-minute anatomy review to six different groups of students helped them improve their delivery of information and to tailor it to their audience. In fact, $82.0 \%$ of the DPT students claimed that teaching portions of the IPE cadav- 
er-based anatomy lab positively increased their communication skills with other healthcare professionals while $100 \%$ of the DPT students stated their teaching skills were also improved. In regards to their comfort level in communicating with other healthcare professionals, one DPT student stated, "Prior to this course I really hadn't had much of any experience communicating with other healthcare professionals so this provided me the opportunity to do so to increase both my skills as well as my confidence in doing so".

Currently, one of the most pressing concerns of patient care is the compartmentalization of the expertise of varying medical fields, which can lead to a lack of collaboration ultimately resulting in lost opportunities to build mutual trust and respect amongst healthcare providers. To build mutual trust and respect healthcare providers must be aware of one another's medical specialties and educational backgrounds. For the DPT students and the CRNA students, the cadaver-based anatomy IPE course allowed both groups of students to not only learn about each other's medical profession but also led to increased respect for the knowledge level each other holds concerning their specialties. The results of the quantitative survey showed that $82.0 \%-86.0 \%$ of the DPT and CRNA students felt that the IPE experience helped them to understand another healthcare profession. A comment from a CRNA student summarized the importance of developing mutual respect for one another with the statement, "The respect shown between highly driven professional students in higher education was both inspiring and refreshing. I had a higher regard for their [DPT] expertise after the session and I truly felt that to be a mutual respect. This made communication a pleasure". Another CRNA student noted, "I have worked with many PT's as a nurse in the unit and I truly didn't give them the credit they deserved. So I have learned that everyone has worked hard and learned a lot to work in healthcare". This is similar to the findings in a study by Hamilton et al. in regards to the experience of working in a cadaver lab with the DPT students, in which the MD students developed increased respect for the DPT students' training [7]. Another point of interest was the sharing of learning mnemonics between the DPT and CRNA students as well as some general terminology that is not commonly used in one another's area of expertise. A unique comment that was provided by one of the CRNA students was one regarding the word "appreciation". The CRNA student commented, "The therapists used 'appreciate' when describing elements of the cadaver. I will have a greater appreciation for organ donors, and medical providers who sacrifice to help others". A DPT student commented, "What is most enjoyable about interacting with other healthcare professionals is that I feel it helps build mutual respect. You really get a feel for how knowledgeable they are and for me it helps build confidence going forward. The exposure this course allowed further emphasized that we are all working to the same goal of bettering the patient".

Data from this study which demonstrated an overwhelmingly positive response from those involved, supports the assertion that a team-based approach to healthcare delivery can maximize the individual skill-sets and expertise of 
each contributing healthcare worker [2]. While there are certainly some limitations to this study, any educational experience in which $96.6 \%$ of the CRNA students would recommend this experience to others in their field, and $100 \%$ of the DPT students felt like the experience assisted in their anatomy retention, is a positive outcome. Limitations include the fact that there was a small sample size of DPT students, and information collected pertained to a single event rather than looking at longitudinal data which certainly limits the overall generalizability of the outcomes. Other limitations include the fact that much of the data collection was focused around surveys and opinions rather than objective testing regarding how the educational experience may help with future interactions as well as how the anatomy course helped with overall understanding of and retention of anatomy information. While data from this experience strongly supports this type of IPE, future research is needed regarding some of the qualitative assertions made. Specifically, future research is needed to assess retention of anatomy material to determine the actual effectiveness of this IPE experience. Additionally, the long-term impact of this IPE experience on attitudes of various healthcare professionals might be a worthwhile area of future study.

\section{Conclusion}

Providing a cadaver-based learning opportunity for students who could directly benefit from learning in this type of setting may offer a solution to both the lack of exposure to cadaver-based learning for many students pursing healthcare degrees, such as nursing students, while simultaneously providing an opportunity for an IPE experience within a cadaver laboratory. Given IPE experiences are becoming more popular, and many nursing programs are located at universities that coexist with schools of medicine and/or physical therapy [11], this type of learning experience has the potential to grow and benefit many of our future healthcare providers [10]. For those educational programs that do not have access to a cadaver laboratory on campus, a cadaver-based anatomy review course, structured similarly to the one described in this paper, may offer a cost-effective solution. In addition to potentially promoting the kinesthetic learning of human anatomy, a cadaver-based review course may cultivate interprofessional teaching and learning opportunities with other future healthcare providers.

\section{Conflicts of Interest}

The authors declare no conflicts of interest regarding the publication of this paper.

\section{References}

[1] Lumague, M., Morgan, A., Mak, D., et al. (2006) Interprofessional Education: The Student Perspective. Journal of Interprofessional Care, 20, 246-253. https://doi.org/10.1080/13561820600717891

[2] World Health Organization. (2010) Framework for Action on Interprofessional Education \& Collaborative Practice. 1-63. 
http://apps.who.int/iris/bitstream/handle/10665/70185/WHO_HRH_HPN_10.3_en g.pdf;jsessionid=C2195D9F4C3B13B95DBC55D0C12B1023? sequence $=1$

[3] Schmitt, M., Blue, A., Aschenbrener, C.A. and Viggiano, T.R. (2011) Core Competencies for Interprofessional Collaborative Practice. Academic Medicine, 86, 1351. https://doi.org/10.1097/ACM.0b013e3182308e39

[4] Bridges, D.R., Davidson, R.A., Odegard, P.S., Maki, I.V. and Tomkowiak, J. (2011) Interprofessional Collaboration: Three Best Practice Models of Interprofessional Education. Medical Education Online, 16, No. 1.

https://doi.org/10.3402/meo.v16i0.6035

[5] Canadian Interprofessional Health Collaborative. (2010) A National Interprofessional Competency Framework.

http://www.cihc.ca/files/CIHC_IPCompetencies_Feb1210.pdf

[6] Barr, H., Koppel, I., Reeves, S., Hammick, M. and Freeth, D. (2005) Effective Interprofessional Education. Blackwell Publishing Ltd., Oxford, UK. https://doi.org/10.1002/9780470776445

[7] Hamilton, S.S., Yuan, B.J., Lachman, N., et al. (2008) Interprofessional Education in Gross Anatomy: Experience with First-Year Medical and Physical Therapy Students at Mayo Clinic. Anatomical Sciences Education, 1, 258-263.

https://doi.org/10.1002/ase.59

[8] Turney, B. (2007) Anatomy in a Modern Medical Curriculum. Annals of The Royal College of Surgeons of England, 89, 104-107.

https://doi.org/10.1308/003588407X168244

[9] Older, J. (2004) Anatomy: A Must for Teaching the Next Generation. Surgeon, 2, 79-90. https://doi.org/10.1016/S1479-666X(04)80050-7

[10] Mc Garvey, A., Hickey, A. and Conroy, R. (2015) The Anatomy Room: A Positive Learning Experience for Nursing Students. Nurse Education Today, 35, 245-250. https://doi.org/10.1016/j.nedt.2014.07.007

[11] Johnston, A. (2010) Anatomy for Nurses: Providing Students with the Best Learning Experience. Nurse Education in Practice, 10, 222-226. https://doi.org/10.1016/j.nepr.2009.11.009

[12] Korf, H.W., Wicht, H., Snipes, R.L., et al. (2008) The Dissection Course-Necessary and Indispensable for Teaching Anatomy to Medical Students. Annals of Anatomy, 190, 16-22. https://doi.org/10.1016/j.aanat.2007.10.001

[13] Simpson, J.S. (2014) An Economical Approach to Teaching Cadaver Anatomy: A 10-Year Retrospective. The American Biology Teacher, 76, 42-46. https://doi.org/10.1525/abt.2014.76.1.9

[14] McLachlan, J.C., Bligh, J., Bradley, P. and Searle, J. (2004) Teaching Anatomy without Cadavers. Medical Education, 38, 418-424. https://doi.org/10.1046/j.1365-2923.2004.01795.x

[15] Brenton, H., Hernandez, J., Bello, F., et al. (2007) Using Multimedia and Web3D to Enhance Anatomy Teaching. Computers \& Education, 49, 32-53. https://doi.org/10.1016/j.compedu.2005.06.005

[16] Barr, H. (2002) Interprofessional Education Today, Yesterday and Tomorrow: A Review. LTSN for Health Sciences \& Practice. https://www.unmc.edu/bhecn/_documents/ipe-today-yesterday-tmmw-barr.pdf 